\title{
Metafísica empírica ou empirismo radical: Bergson e a superação fenomenológica do intelectualismo representacionista
}

\author{
Empirical metaphysics or radical empirism: Bergson and the phenomenological \\ overcoming of the representacional intellect
}

João Batista Magalhães Prates ${ }^{1}$

\begin{abstract}
Resumo: Este trabalho procura descrever, de maneira sucinta, o método bergsonista. Para isso, sugere aproximações entre o bergsonismo e a fenomenologia naquilo que se propõe um "empirismo radical", ao mesmo tempo que demonstra a sua superação ao encaminhar-se do fenomênico ao real, do para si ao em si. Na busca da realidade em si mesma o bergsonismo descortinará uma realidade ampliada para além dos quadros do intelectualismo clássico, ombreando as pesquisas surrealistas do romantismo e da Escola de Frankfurt, somando-se a eles naquilo que empenharão a crítica à razão instrumental entendida como o todo das possibilidades da razão, concepção racionalista herdada da modernidade positivista que, em última instância, reifica o mundo natural e opõe ser humano e natureza de forma radical. A superação deste estreitamento da razão resolverá não só problemas teóricos da História da filosofia: a aposta de Bergson é que fazê-lo significará a um só tempo elevar o padrão moral da humanidade.
\end{abstract}

Palavras-chave: Bergsonismo. Razão instrumental. Aceleração do tempo.

Abstract: This paper intends to describe, summarily, the method in Bergson's philosophy. To do so, it suggests affinities between bergsonism and phenomenology regarding its "radical empirism", at the same time demonstrating its surpass by passing from the phenomenical to the real itself. In this search of real itself, the bergsonism unveils a much wider reality than the one out classical intellectualism gave us, going hand to hand with the surrealitic researches of romantism and the Frankfurt School, especially in that they will all criticize the conception of purely instrumental reason as the hole of reason. This is the conception of the classical rationalism inherited from positivism and that, ultimately, reifies the natural world, opposing natural and cultural in a irreconcilable way. Surpassing this narrowing of reason will solve not only theoretical issues, but also the moral ones.

Keywords: Bergsonism. Instrumental rationality. Acceleration of time.

\section{Bergsonismo: uma fenomenologia anacrônica?}

\footnotetext{
${ }^{1}$ Graduado e mestrando em Filosofia pela UNIFESP, bolsista CAPES-DS. E-mail: batistaprates1 @ gmail.com. Artigo recebido em 06/05/2020 e aceito em 29/06/2020.

Perspectivas - Revista do Programa de Pós-Graduação em Filosofia da UFT - volume 5, n. 1 - 2020
} 
Há uma discussão posta a respeito da possível filiação (lógica, evidentemente) do bergsonismo com a fenomenologia, dada a centralidade da intuição. Decerto, se tomamos o conceito tal qual definido pelo seu idealizador, Husserl, teremos que a comparação é indevida, uma vez que

fenomenologia, como método, é o estudo das estruturas da consciência tais como elas são experienciadas do ponto de vista de alguém que as vive em primeira pessoa. De acordo com Husserl, a fenomenologia não se aventura em questões relativas à nossa capacidade de obter conhecimento de coisas reais objetivas a partir da natureza dos objetos mesmos fornecidos pela experiência, nem considera se esses objetos possuem de fato existência real (...) isso significa que nenhuma investigação ontológica pode ser impostada por meio da fenomenologia. (POSTIGO, 2016, p. 260-261).

Os discípulos de Husserl, entretanto, desenvolveram a fenomenologia levando o método do mestre a campos que este jamais pretendeu alcançar, fazendo a crítica do que seria o idealismo do mestre. É o que fará Edith Stein, por exemplo.

A abordagem de Edith Stein, que entrelaça fenomenologia e ontologia, já pode ser encontrada desde a sua tese de doutorado (...) Edith percebe que, diferentemente do que em geral se presume, a análise da experiência oferece um solo mais fértil quando incorpora as camadas da experiência permitida pelo corpo. Ainda que Merleau-Ponty tenha tomado, mais tarde, o caminho da consideração da estrutura do corpo em Fenomenologia da percepção, a via de Edith Stein permanece única no seguinte sentido: ela percebeu que o foco intencional não é mediado apenas pela cognição ou pela percepção, mas também por um novo tipo de intencionalidade, ao qual eu chamaria de intencionalidade afetiva (ou afeccional). (POSTIGO, 2016, p. 274-275)

Como Bergson, há o esforço - esforço que perpassa toda a História da Filosofia dogmática, entendida como aquela que afirma sobre o mundo, que produz dogma, e não aquela que procede sem crítica - de dar o salto de uma epistemologia a uma ontologia metafísica. Em Stein o mesmo se sucede a partir da reflexão sobre o corpo próprio e suas modalidades de percepção intuitivas. Esse trabalho versará sobre a concepção de conhecimento, comum às filosofias vitais e às fenomenologias, de um outro modo de conhecer que implica a relação direita com o objeto do conhecimento, em uma (quase) ausência da mediação considerada necessária, senão ao intelecto, pelo menos ao intelecto entendido como inteligência fabricadora ou razão geométrica.

O racionalismo clássico, desde Platão, separa o corpo da alma. A parte não geométrica do humano foi considerada irracional: não se podia operar com ela. O campo do emocional estivera associado ao excesso desde há muito. Mas o conceito de "physis" no mundo clássico entendia que o corpo humano e o mundo cultural humano, produzido pela razão, são ainda 
interiores e não opostos à natureza (entendida como natura naturans). Há ratio no excesso, ainda que seja para contrastá-lo com a moderação que a razão natural apontaria como melhor fim. A perdição moderna é a negação da própria imersão e coincidência do corpo humano com o cosmos. No Renascimento a cisão se opera e funda-se o abismo que separa razão e emoção, intelecto e corpo, ficando em geral a segunda ao mesmo nível da loucura. Lembremos aqui como Freud, apesar de retomar as pesquisas da ratio da loucura, rejeita a existência de um sentimento como o "amor universal" ou de "ligação com o todo do cosmos" logo no início de "O mal estar na civilização": tratava-se de uma ilusão da razão não liberta de seu estágio monístico primitivo. Mas não foi preciso esperar até o romantismo e as filosofias vitais, nem por Freud e os fenomenólogos para que o eixo fosse alterado: Pascal já anunciava uma ruptura com a tradição que desconfiava sobremaneira dos sentimentos. É bem conhecida a fórmula do bergsonismo, entretanto, de que está no caráter singular de uma experiência emocional específica (o "amor universal"), que nos invade e arremata em direção a uma finalidade altruísta, a verdadeira bússola e medida de uma ética profunda, metafísica. À metafísica se delega, além de todos os objetos clássicos desse campo, toda reflexão a respeito do mutável, do móvel, do vivo que progride no tempo, uma vez que essas realidades não se mostram adequadas ao instrumental da inteligência, que progride em sua ciência justamente por imobilizar o móvel e dividir o uno. No que segue pretendemos demonstrar como que da análise e descrição dos processos de consciência (a redução fenomenológica) e do mecanismo da percepção imediata o bergsonismo desvenda, na esteira que trilhará a fenomenologia posterior, uma série de realidades que teriam passado ao largo da aparelhagem lógico-científica de exploração do mundo, realidades sobretudo temporais, como os nossos estados de consciência e nossas motivações profundas; realidades unitárias como o cosmos. Operar-se-á uma espécie de volta à concepção clássica de physis e o que era relegado ao campo da emoção alçará uma posição relativa ao conhecimento.

Tomemos por exemplo a intencionalidade afetiva, ou empatia, que na obra de Edith Stein "é experimentada como uma compreensão de uma consciência alheia, sem todavia operar por inferências" (POSTIGO, 2016, p. 277). Trata-se, portanto, de uma intuição ou percepção complexa de objetos. "À medida que nos tornamos parte de um fluxo de experiência compartilhada com outro sujeito, nós podemos chegar a uma compreensão dos correlatos objetivos de seus próprios atos empáticos" (POSTIGO, 2016, p. 280). Aqui estamos diante do que Bergson chamou de "coincidência do sujeito com o objeto" no processo de conhecimento. Tal conceito de intuição como forma de conhecimento a recusa do intelectualismo 
representacionista da tradição, segundo o qual conhecer é exclusivamente proceder por operações abstratas de similares dos objetos reais. Para além, recusa também a concepção do mundo como dividido ou fraturado entre natureza e cultura; entre corpo e intelecto. Muito embora o intelecto não se reduza ao corpo ao modo do materialismo, ele tampouco pode operar ou ser colocado em processo sem o corpo.

De fato, nossas vivências ordinárias da empatia começam com uma experiência em primeira pessoa, mas essa experiência, como Edith Stein reconhece, não é apenas a experiência de uma ideia de algo no mundo. Antes, é uma experiência de algo no mundo que somos capazes de perceber diretamente, julgar e detectar afetivamente. Nossos corpos são, portanto, não uma camada intermediária que nos separa do mundo, mas, em vez disso, o dinamismo de orientação que por si mesmo nos permite inteirar-nos do mundo diretamente e ser parte dele. (POSTIGO, 2016, p. 290)

\section{Crítica do intelectualismo representacionista: da coincidência entre sujeito e objeto}

Quando Husserl funda a fenomenologia e volta a falar de "essências" a opinião pública o teria declarado um "escolástico" ressuscitando velharias de uma metafísica clássica há muito proscrita. Em nada poderiam estar mais enganados, uma vez que se falava em essências era em um sentido bastante diverso daquele mobilizado pelo que se entendia à época pelo pensamento de Tomás de Aquino, por exemplo (concepções aristotélicas que a escola do pensamento histórico de Tomás mostrariam inacuradas). A essencialidade na fenomenologia entendida enquanto método filosófico (condizente nessa qualidade de método apenas à epistemologia, portanto) é identificada com o modo de doação dos objetos à percepção paradigmática da humanidade. É ela que afasta os relativismos com a constatação muito simples da intersubjetividade. $\mathrm{O}$ artifício, entretanto, jamais poderia (e jamais o pretendeu) conduzir a uma ontologia em termos clássicos (ontologia metafísica), uma vez que não teríamos garantia se o que pensamos (ainda que intersubjetivamente) sobre o mundo é de fato aquilo que ele é. Esse é o "idealismo transcendental" de Husserl criticado por seus discípulos. Edith Stein foi uma das principais alunas de Husserl e pretendeu levar o método fenomenológico para além da epistemologia, conectando conhecimento, ser e verdade. O ponto central do debate é que há uma violência original do objeto que impõe sua forma à percepção, que se não é inteiramente passiva, operando no ato de percepção, tampouco é inteiramente ativa e não produz tudo - como queria um certo idealismo transcendental de ênfase kantiana. O novo paradigma passa a ser o da inter-relação e coincidência entre o sujeito que percebe e o objeto percebido. Sujeito e objeto caminharão nessa via no sentido da superação da moderna - e abstrata - separação entre os dois 
pólos que se quis estanques; significará, enfim, a reinserção do ser humano ao todo da natureza (entendida enquanto physis), através do conceito de corpo próprio. A consciência aparece enquanto centro de conjugação de múltiplos processos de ação e reação, não mais como tábula rasa onde se inscrevem e se gravam conteúdos. Sendo sempre "consciência de" a consciência supõe uma relação, não podendo ser uma coisa. Tal concepção alargada da consciência (já há muito tempo convocada por Bergson, desde o Ensaio Sobre os Dados Imediatos da Consciência) significará a descoberta de novas formas de percepção e, portanto, de conhecimento, não necessariamente redutíveis à razão lógico-discursiva, como supunha o paradigma intelectualista anterior. Há uma (longa) nota em "Fenomenologia da percepção" que nos parece uma boa via para alçar e compreender a crítica. Lá se lê:

Não é fácil evidenciar a intencionalidade motora pura: ela se esconde atrás do mundo objetivo que contribui para constituir. A história da apraxia mostraria como a noção de representação quase sempre contamina e finalmente torna impossível a descrição da Práxis. (...) Todo o aparelho sensoriomotor de um membro está, por assim dizer, desarticulado do processo fisiológico total (ibid., pp. 40-41). Normalmente, portanto, toda fórmula de movimento, ao mesmo tempo em que se oferece a nós como uma representação, se oferece ao nosso corpo como uma possibilidade prática determinada. A apraxia só se tornará compreensível, só se fará justiça às observações de Liepmann se o movimento a fazer puder ser antecipado, sem sê-lo por uma representação, e exatamente isso só é possível se a consciência é definida não como posição explícita de seus objetos, mas, mais geralmente, como referência a um objeto prático tanto quanto teórico, como ser no mundo, se o corpo, por seu lado, é definido não como um objeto entre todos os objetos, mas como o veículo do ser no mundo. Enquanto se define a consciência pela representação, a única operação possível para ela é formar representações. A consciência será motora enquanto ela se der uma "representação de movimento". O corpo executa então o movimento copiando-o da representação que a consciência se dá e segundo uma fórmula de movimento que recebe dela. Resta compreender por qual operação mágica a representação de um movimento suscita justamente no corpo esse próprio movimento. O problema só se resolve se deixamos de distinguir o corpo enquanto mecanismo em si e a consciência enquanto ser para si. (PONTY, 1999, p. 630-631)

\section{Intuição e intencionalidade do corpo próprio: da ampliação da percepção}

Ao criticar a concepção da estrutura discursiva da consciência, segundo a qual todo conteúdo da consciência seja pensamento que envolve abstração e síntese, a fenomenologia nos abre o campo da "intuição". Em Bergson o procedimento da redução fenomenológica, do voltar-se para a descrição dos processos da consciência quando ela opera em si mesma, na imediatez maior que nos é possível (ou nas fases anteriores ao exercício dirigido do pensamento analítico - ou inteligência fabricadora), desvenda-nos a continuidade do Ser do mundo, 
continuidade essa que engolfa nosso corpo como centro de inter-relação e vivência. A evidência então, fundamento da certeza, é dada não no juízo ou no discurso sobre o que é; não é produzido por meio de uma análise já comprometida com uma prévia teoria. A volta à realidade operada pela fenomenologia descobre a evidência no vivido, que deve ser tão somente descrito. A fenomenologia não se coloca, portanto, como teoria sobre a consciência (como fizeram as filosofias dogmáticas), mas como uma descrição dos processos segundo os quais a consciência opera. Ora, o que nos garante que ao (inter)subjetivismo assim concebido corresponde alguma realidade "no mundo das coisas"?

Toda consciência é sempre intencional (ou intensional), no sentido de que remete ao estado de tensão que prepara uma atividade - exatamente como a corda retesada de um violino produzirá som ao atrito. A alma é entendida agora não como coisa que habita a outra coisa do corpo, mas justamente como o estado de tensão deste corpo retesado que age e reage a tudo o que o cerca - a memória, na compreensão do bergsonismo, não é mais do que uma função retesada deste corpo em sentido amplo, voltado para a ação, muito embora não se encontre depositada nele como a água em um vaso, ao modo de pensar do materialismo. Essa compreensão de que os objetos com os quais estamos em relação nos solicitam de uma forma violenta, que eles se colocam a nós que reagimos a eles, trai a realidade do mundo, à qual tanto Bergson quanto Edith Stein proclamarão confiança, amparados no sentimento da evidência. A consciência, portanto, somos nós em nossa relação com as coisas que nos aparecem, não um baú onde as depositamos na condição de imagens mentais, subtraídas de sua materialidade. É um conjunto de atos que acontecem de forma múltipla; um fluxo de vivências só muito precariamente captado pela análise retrospectiva que lhe deita a inteligência, operando sempre sobre os atos do instante presente que já escapou e deixou atrás de si uma infinidade de movimentos distintos que unimos em uma tonalidade geral e artificial de sentido como a costureira que junta diversos retalhos em uma só malha de tecido. Bergson será um entusiasta das possibilidades para pensar a captação de objetos e sentidos em processos gerais através do alargamento dessa atenção à multiplicidade dos processos de consciência. O novo aqui é que podemos saber de algo sem que o seja somente pela via da inteligência fabricadora (ou da racionalidade científica), com sua exigência da clareza e distinção: há percepção clara de uma realidade indistinta também. A poesia e sua linguagem como forma de transmissão desses sentidos complexos e densos demais para a análise tem exercido desde muito tempo um fascínio sobre os filósofos da intuição e do misticismo. Assustamo-nos perante um quadro oferecido pela melhor literatura a respeito do desenvolvimento de tendências só precariamente captadas, 
mal intuídas no instante presente, como que antecipando um desenvolvimento histórico décadas à frente, justamente porque $\mathrm{o}(\mathrm{s})$ futuro(s) se delineava(m) nessas entranhas do presente e mantiveram com ele fios de continuidade.

A consciência não opera refletindo ou contendo o objeto em sua forma abstrata, mas o englobando e sorvendo ao travar relações múltiplas com ele - relações essas que não se dão exclusivamente por mão única. O rigor da redução fenomenológica está em fazer a consciência ser guiada, por assim dizer, pelo objeto, ao invés de buscar abordá-lo a partir de uma construção teórica prévia. A consciência aparecerá como transitiva: está sempre a responder estímulos externos e internos. A busca pela consciência pura, ou seja, a consciência enquanto rede que se estende para receber conteúdos antes de os ter recebido, nos é impossível conhecer, uma vez que ela está sempre em relação e respondendo a algo. Mas em certos estados de consciência, como aquele que procede imediatamente ao acordar, percebemos um seu funcionamento mais vazio de conteúdo que nos desvela a atividade mesma da consciência, para além de sua passividade. Consciência, portanto, será o nome que se dá ao encontro entre o polo subjetivo e o objetivo. Um estar na presença do outro é a consciência. Ela supõe a existência do mundo e a possibilidade que temos de conhecê-lo, ou seja, a possibilidade de que haja coincidência entre a consciência que temos do mundo e o mundo tal qual ele se nos apresenta, não precisaria ser posta em dúvida, uma vez pudéssemos separar o conteúdo noemático (e pessoal, portanto) de uma percepção do seu conteúdo intersubjetivo. Há, entretanto, o problema das diferentes culturas, que enredam um conjunto da humanidade em construções noemáticas comuns e compartilhadas apenas entre si - tal problema estende-se principalmente sobre os valores humanos e pode nos levar a relativizar a ética. Seja como for, deixando o problema ético do dever ser momentaneamente de lado, estaremos às voltas novamente com o mesmo procedimento de Galileu quando dividiu o mundo da consciência em duas categorias distintas: percepção de qualidades primárias e secundárias dos objetos, sendo as primárias identificadas com a matéria espacial e reduzidas a tudo o que podemos conhecer - era o início do paradigma cientificista que desalojaria do templo do saber vastas porções do real que se oferecem à nossa percepção?

Em alemão há duas palavras para se referir ao "corpo" humano. A primeira é "korp" e equivale ao corpo da medicina, entendido como porção de matéria em uma perspectiva não holística ou integrada, que funciona segundo as leis da causalidade. Há, porém, o "leib" que equivale ao conceito de "corpo próprio", esse campo de ação e reação que tem o korp por centro de referência e se estende dele a tudo o que com ele se relaciona. Trata-se do corpo vivenciado 
que assumo como meu quando atuo no mundo - e não quando penso sobre essa atuação. Esse corpo faz o cômputo de tão múltiplas relações que um conceito não dá conta de defini-lo. Só podemos recorrer às descrições, sempre podendo progredir em seu grau de detalhamento e precisão, ao infinito. Ascender à intuição desse corpo em ato é fazer o caminho que nos leva de volta ao conceito abandonado de physis: o ser humano já não se percebe como ponto material isolado dos demais pontos materiais no espaço, entremeados pelo vazio, mas como uma ponte ou elo de ligação inserido em um campo espacial de múltiplas relações e continuidades. É nesse sentido que entendemos o famoso exemplo da bengala do Ponty. A bengala, tal como descrita em seu uso em Fenomenologia da perceção (p. 197), não é simplesmente justaposta ao corpo, mas adere ao corpo e se torna parte dele, modificando-lhe o campo de ação e as suas formas de reação. Quando se usa uma bengala não se representa o seu uso (fazê-lo mesmo impediria os movimentos desembaraçados), mas se a usa simplesmente, e nesse ato de usá-la ampliamos o corpo próprio. A revelação do corpo próprio é uma intuição mística - se o misticismo está ligado à compreensão da unidade do todo, como em Bergson.

Se meu braço está posto sobre a mesa, eu nunca pensaria em dizer que ele está ao lado do cinzeiro do mesmo modo que o cinzeiro está ao lado do telefone. O contorno de meu corpo é uma fronteira que as relações de espaço ordinárias não transpõem. Isso ocorre porque suas partes se relacionam umas às outras de uma maneira original: elas não estão desdobradas umas ao lado das outras, mas envolvidas umas nas outras. Por exemplo, minha mão não é uma coleção de pontos (...) a partir do momento em que quero tematizar o espaço corporal ou desenvolver seu sentido, só encontro nele o espaço inteligível. (PONTY, 1999, p. 143-148).

"Nessa medida, até mesmo os reflexos têm um sentido, e o estilo de cada indivíduo ainda é visível neles assim como o batimento do coração se faz sentir até na periferia do corpo." (PONTY, 1999, p. 126). Evoca-se a integralidade do fluxo temporal, sendo o presente-do-futuro a ponta de uma onda de presentes-do-passado, sempre desenvolvendo-se. Por isso o que vêm a se desenvolver é sempre desdobrado do que era, carregando seus sinais. Se isso é verdade para os atos individuais, tão mais para os atos de povos inteiros. Se tudo é refluxo de experiência complexa comprimida, tudo informa e se pode ler em tudo, mesmo nos menores detalhes, pistas de sentido - lembremo-nos da saudosa passagem bergsonista em que ele diz que o escritor transporta ao seu estilo literário todo o seu ser como se sua produção fosse uma extensão de si mesmo. Essa captação de sentido, entretanto, não necessariamente se fixa à inteligência fabricadora, que atua apenas depois da percepção já realizada, para analisá-la e fixá-la. É preciso muita capacidade analítica e potências do espírito (sobretudo memória e uma capacidade de concentração) para analisar esse mar de dados que se oferece condensado em 
uma única gota da percepção para desdobrar desse ato intuitivo as formulações discursivas e explicativas mais certeiras. Aqui se explicita a diferença da vivência do corpo próprio para a atividade propriamente fabricadora da inteligência geométrica, que vê pontos e paradas onde há fluxo e movimento:

precisamos forjar os conceitos necessários para exprimir que o espaço me pode ser dado em uma intenção de apreensão sem me ser dado em uma intenção de conhecimento. $\mathrm{O}$ doente tem consciência do espaço corporal como local de sua ação habitual, mas não como ambiente objetivo, seu corpo está à sua disposição como meio de inserção em uma circunvizinhança familiar, mas não como meio de expressão de um pensamento espacial gratuito e livre. (PONTY, 1999, p. 151)

Fica evidente haver formas de percepção corporais, por assim dizer, vivenciadas antes de serem racionalizadas - movimento este sempre retrospectivo, como bem nos demonstrou Bergson. $\mathrm{O}$ objeto encarnado (ou o sujeito habitado) é percebido e captado intuitivamente, embora ganhe contornos intelectuais em um movimento retrospectivo de análise e tradução do captado. Desvenda-se assim a trilha da proposta do bergsonismo para derrubar a diferença moderna entre ciência e metafísica de uma vez por todas. Ele diria:

Queremos uma diferença de método, não admitimos uma diferença de valor
entre a metafísica e a ciência. Menos modestos no tocante à ciência do que foi
a maioria dos cientistas, achamos que uma ciência fundada na experiência, tal
como os modernos a entendem, pode alcançar a essência do real. É certo que
ela abarca tão somente uma parte da realidade; mas dessa parte poderá um dia
tocar o fundo; em todo caso irá se aproximar dele indefinidamente. Portanto, já
satisfaz metade do programa da antiga metafísica: metafísica ela poderia se
chamar se não preferisse conservar o nome de ciência. Resta a outra metade.
Esta nos parece competir de direito a uma metafísica que também parte da
experiência e que também tem condições de alcançar o absoluto: chamá-la-
íamos de ciência se a ciência não preferisse limitar-se ao resto da realidade.
Portanto, a metafísica não é superior à ciência positiva; não vem, depois da
ciência, considerar o mesmo objeto para obter dele um conhecimento mais
elevado. Supor entre elas essa relação, segundo o costume mais ou menos
constante dos filósofos, é prejudicar a ambas: à ciência, que se vê condenada à
relatividade; à metafísica, que não será mais do que um conhecimento
hipotético e vago, já que a ciência terá necessariamente tomado para si, de
antemão, tudo o que se pode saber de preciso e certo sobre seu objeto.
(BERGSON, 2006, p. 43-44.)

A verdade objetiva e absoluta seria aquela que nos é dada de maneira mais imediata, compreensível imediatamente sem que o raciocínio lógico (ou a inteligência fabricadora) intervenha a título de mediação. Tal acesso direto do em si, que se dá agora na imanência, não é um juízo, mas uma percepção (inclusive a que chamamos "intuição", que acrescenta um sentido interior aos cinco sentidos voltados para o "fora" do corpo humano, e que Bergson chamaria de "consciência"). Tal concepção da consciência enquanto relação de si consigo 
mesmo afasta o intelectualismo que entendia o conhecimento em termos de representação e que seria, de acordo com o bergsonismo, o sentido natural da nossa inteligência. Ascender à nova concepção do corpo próprio, de consciência, do movimento e do cosmos requereria um esforço gigantesco e por assim dizer antinatural (embora interior à natureza entendida como natura naturans). Os artistas seriam os únicos que, por uma falha da natureza, estariam naturalmente voltados para o uso alargado da razão (ou da percepção) e para a concepção das unidades e continuidades. Haveria um método filosófico, contudo, através do qual poderíamos treinar a nossa percepção para o alargamento - eis a concepção de filosofia também enquanto terapia, em Bergson.

\section{Considerações finais}

O salto da concepção e percepção da unidade do tempo e do movimento para a unidade das coisas e dos processos percebidos no mundo redundará em uma nova metafísica em que a noção de vazio e separação completa não fará mais sentido. Os processos que se abrem ao conhecimento são também processos da consciência e da subjetividade como um todo, de mim mesmo e das outras pessoas. Temas filosóficos como felicidade e amor, que ombreiam a

psicologia, são esses objetos novos que se dão a conhecer objetivamente, ainda que com o concurso do exame subjetivo. Mas também a psicologia de um grupo de pessoas; de um tipo de pessoas. A intuição de tendências de futuro - como o é a identificação da destrutividade da técnica, por exemplo. Em ética está o outro campo que a intuição nos abre (e em teologia): ao conceber o homem como unidade com a natureza, a exploração biocida da natureza se mostra perigosa à sobrevivência da espécie. A visão ecológica só faz sentido uma vez que se rompa com as categorias espaciais da inteligência - e isso a fenomenologia fez, e o fez também o misticismo. Definir misticismo pela concepção da unidade ou continuidade - opondo-se à concepção da separação e do corte - é profícuo aqui. Ascender à concepção da natureza enquanto physis que engolfa o próprio corpo humano é ascender à compreensão do corpo próprio. Nesse balaio a poesia e a mitologia ditirâmbica aparecem como forma de captar esse todo ou ascender à intuição da totalidade ou da continuidade dos seres, o que explica-se na própria forma da poesia, que o facilita. Ela nos retira de toda espacialidade (e de toda representação intelectualista) para nos levar ao campo do temporal, em que tudo aparece como contínuo e não separado. A unidade integrada da poesia prenuncia a unidade do real. 
A aceleração do tempo desde a modernidade, porém, significa a um só tempo a aceleração dos fluxos de consciência. Os estados mentais se sucedem em tal velocidade que a atenção já se vê incapaz de acompanhá-los e já sem tempo de meditar sobre eles, posterior e retrospectivamente. As racionalizações do comportamento humano que outrora, tradicionais, serviam de guia às ações humanas e nos situava no mundo, agora pulverizam-se em imediatismos que por definição são alheios a qualquer tipo de acumulação de experiência. $O$ tempo do presente eterno é o dispêndio de tempo de vida em que se abre mão, senão da previsibilidade do futuro (uma vez que as estruturas montadas para garantir que as experiências se repitam os infinito roubam o lugar da ciência), da vontade de aperfeiçoamento do homem e de suas relações. Abre-se mão do progresso entendido como não repetição, mas avanço rumo ao novo e melhorado. Criticar, refletir, examinar, analisar são todas palavras que remetem à operação geométrica da divisão pormenorizada de um objeto que se pretende estudar e compreender. Se se trata de um objeto da experiência, indivisível que é enquanto se dá no sujeito, pode ser entretanto submetido ao crivo da inteligência divisora tão logo ele passe e se funde um distanciamento entre sujeito e sua experiência subjetiva real, que será reproduzida pela memória. Para que esse exame aconteça é necessária a pausa, a suspensão do fluxo da vida prática diária. O retiro é necessário mesmo para que se perceba, na suspensão do fluxo do real, que a realidade é continuidade indivisível. A sociedade contemporânea não pode oferecê-lo e nos repõe indefinidamente à roda rápida, que gira inconscientemente. Imersos no fluxo dos acontecimentos já não temos qualquer controle sobre eles - sequer o controle precário que a acumulação da experiência intersubjetiva havia nos legado até aqui, e que passávamos às gerações seguintes pela cultura oral. Alcançamos uma espécie de unidade perceptiva, mas não refletida: uma unidade que não se sabe una, como a experiência dos demais animais. Por não produzi-la e nem presenciá-la acreditar-se-á que a ruptura é impossível e impossível o progresso: perde-se a noção mesma de progresso. O "para onde ir" será dado pelos mecanismos obscuros que apenas alguns privilegiados parecem ter, como dom de entender, e a finalidade que descortinam é a mesma que opera no cotidiano à plena luz, a saber, a manutenção do já posto, ou mesmo a eliminação das contradições residuais que impedem ao princípio hegemônico a sua plena realização. Só o trauma pode retirar o sujeito assim constituído do trilho e forçá-lo ao exame e cuidado de si mesmo em busca das respostas capazes de sanar suas urgências. O traumatizado, entretanto, carregará o estigma de jamais poder reincorporar-se à montanha russa que o entretinha. Pagará a salvação com a solidão. Onde o consolo de nosso herói, místico, evadido? A filosofia da intuição repõe as já antigas imagens da solidão em filosofia, a exemplo do Zaratustra e do homem liberto da caverna platônica. 


\section{Referências}

BERGSON, H. As Duas Fontes da Moral e da Religião. RJ: Zahar Editores, 1978.

. A Energia Espiritual. São Paulo: Martins Fontes, 2009.

. A Evolução Criadora. Rio de Janeiro: Zahar Editores, 1979.

Aulas de Psicologia e de metafísica. São Paulo: Martins Fontes, 2014.

. Ensaio sobre os dados imediatos da consciência. Lisboa: Edições 70, 2008.

. Matéria e Memória. São Paulo: Martins Fontes, 1999.

O pensamento e o movente: ensaios e conferências. São Paulo: M. F., 2006.

PONTY, M. M. A Fenomenologia da Percepção. Tradução de Carlos Alberto Ribeiro de Moura, ed Martins Fontes, SP, 1999.

SAVIAN FILHO, J. Edith Stein para além do debate "idealismo versus realismo". In: MAHFOUD, M. \& SAVIAN FILHO, J. (org.). Diálogos com Edith Stein: Filosofia, Psicologia, Educação. São Paulo: Paulus, 2017, p. 203-256.

STEIN, E. Textos sobre Husserl e Tomás de Aquino. Ed. Juvenal Savian Filho. Vários tradutores. São Paulo: Paulus, 2019.

ZUÑIGA Y POSTIGO, G. Ontologia fenomenológica: a terceira via de Edith Stein. Teologia em questão: Edith Stein - Estudos críticos. Revista da Faculdade Dehoniana, 30 (2016), p. 259-292. 